\title{
Leitores orgulhosos, leitores envergonhados: As emoções em discursos sobre a leitura'
}

\author{
LUZMARA CURCINO \\ Universidade Federal de São Carlos (UFSCar - SP) \\ Brasil \\ luzcf@ufscar.br
}

Proud Readers, Ashamed Readers - Emotions in Discourses About Reading

(Recibido: 22-12-202O; aceptado: $\left.05^{-\mathrm{O} 5}-2 \mathrm{O} 2 \mathrm{I}\right)$

Resumo. Entre os modos de se referir à leitura, previstos pelos discursos sobre essa prática, encontram-se dois estados anímicos de se enunciar como leitor: a 'vergonha' e o 'orgulho'. No Brasil, onde as distâncias sociais são justificadas muitas vezes pela distinção cultural entre os sujeitos, é importante reconhecer o quanto esse álibi cultural enseja maneiras de se expressar em relação à leitura vinculadas a essas duas emoções. A análise dessa dimensão afetiva do funcionamento dos discursos visa a melhor compreender por que e como se inscrevem esses estados anímicos em textos sobre a leitura e qual é seu impacto e alcance sobre as formas como os sujeitos se identificam ou não com essa prática. Apoiada em princípios da Análise de discurso, da História cultural da leitura e da História das sensibilidades, analiso um enunciado sobre a leitura no qual se explora um tipo específico de 'vergonha', a 'vergonha alheia' relacionada a uma declaração do ex-presidente Luiz Inácio Lula da Silva sobre essa prática. Considerada polêmica, essa declaração circulou amplamente na mídia nacional na ocasião em que foi proferida e, ainda hoje, retorna em diferentes textos e contextos reiterando uma série de discursos consensuais sobre a leitura.

Palavras-chave: discurso; leitura; mídia; vergonha; orgulho.
Abstract. Among the ways to make reference to reading, provided by the discourse regarding this practice, there are two states to consider oneself a reader - "shame" and "pride." In Brazil, where social distances are often justified by cultural distinction, it is important to recognize how this cultural excuse has generated a way to talk about reading tied to these two emotions. The analysis of this affective dimension of operating discourse allows for the better understanding of why and how these states appear in the texts regarding reading. It also shows their reach regarding the ways the subjects identify themselves in this practice. Based on the principles of the discourse analysis, reading cultural analysis and sensibilities history, this paper analyzes a statement about reading where a specific type of "shame" is explored, the "shame of the other," connected to a declaration of the former Brazilian president, Luiz Inácio Lula da Silva, regarding this practice. Considered controversial, this statement circulated among national media at the time it was pronounced, and even today, it comes back in different texts and contexts, reiterating a number of consensual reading discourses.

Keywords: discourse; reading; media; shame; proudness.

\footnotetext{
${ }^{\text {I }}$ Para citar este artículo: Curcino, Luzmara (2022). Leitores orgulhosos, leitores envergonhados: as emoções em discursos sobre a leitura. Alabe 25 · [www.revistaalabe.com] DOI: Io.I5645/Alabe2022.25·3
} 


\section{Discursos sobre a leitura}

Em minhas pesquisas, assim como naquelas que tenho sistematicamente orientado junto ao Laboratório de Estudos da Leitura (CNPq/UFSCar) ${ }^{2}$, tenho me dedicado à análise dos discursos sobre essa prática. Esses estudos visam a melhor compreender o impacto e o alcance dessas formas de enunciar a leitura sobre os modos como essa prática é, assim, concebida, avaliada e exercida (ou não) entre nós.

Como linguista e analista do discurso ${ }^{3}$ concebo cada enunciado em sua condição de "acontecimento", que atualiza certos discursos. O discurso, segundo Michel Foucault (I999), é uma “ordem” histórica, social e cultural, que atua de modo a regular o que se enuncia em sociedade. É essa ordem que organiza, institucionaliza e valida o que em geral é enunciado. É ela que estabelece as regras relativas a quem em geralse outorga o direito de enunciar sobre um dado tema, conforme certos ritos de um campo e segundo os protocolos de uma dada circunstância. Embora em tese, em uma sociedade democrática todos tenham direito à voz, nem todos são efetivamente ouvidos ${ }^{4}$. Essa escuta se relaciona em grande medida com a adequação atribuída àqueles que enunciam e àquilo que enunciam, adequação tributária das condições sócio-históricas dos sujeitos e da vinculação do que enunciam a certos posicionamentos que, mais do que outros, são difundidos e naturalizados na guarida de distintas instituições que lhes outorgam seu valor de verdade. Essa “ordem" é a responsável pelas condições de enunciabilidade em um dado tempo e espaço.

Somos, assim, tema e objeto de discursos e produtores de discursos. O que é dito sobre nós atua na gestão de nossas subjetividades coletivas e institui o que sabemos sobre nós mesmos, assim como as formas segundo as quais nos avaliamos uns aos outros, construímos e mantemos hierarquias. Portanto, para o analista do discurso é fundamental depreender do que é enunciado o(s) discurso(s) que constitui(em) o que foi enunciado, e cujo funcionamento define, em grande medida, nossa relação com as práticas, com os demais sujeitos, com o mundo e com nós mesmos.

Tendo em vista essa atuação subjetivadora dos discursos, responsável pelas formas de identificação e de desidentificação dos sujeitos com as representações que nesses discursos são instituídas, tenho buscado levantar e analisar um conjunto específico de enunciados sobre a leitura, inscritos em textos de jornais e revistas da mídia convencional brasileira $^{5}$, nos quais se expressam certas emoções relativas a essa prática. As emoções

\footnotetext{
${ }^{2}$ Grupo de pesquisa, formado em 2009, cujo compromisso é o de formar pesquisadores na área de estudos dos discursos especializados no tema da leitura. Cf. cadastro no Diretório de grupos de pesquisa do CNPq. Disponível em: http://dgp.cnpq.br/dgp/espelhogrupo/66224762568ıоOо3.

3 A abordagem discursiva adotada neste texto diz respeito àquela relativa à descrita por Michel Foucault em "A Arqueologia do Saber" (2000) e "A ordem dos discursos" (I999). E com base em conceitos e princípios definidos nestas obras que se apoia a análise aqui apresentada.

${ }^{4}$ Cf. a esse respeito, Piovezani (2O2O).

5 Outros pesquisadores do grupo adotam, como fonte para obtenção desses enunciados, textos provenientes do universo digital, desde os mais institucionalizados (portais de notícia, sites oficiais de órgãos governamentais, de instituições comerciais etc.) aos mais pessoais (blogs, canais no Youtube, redes sociais diversas, de anônimos ou de personalidades públicas, de leigos ou de profissionais).
} 
de que tenho me ocupado não são aquelas despertadas pela leitura dos textos ${ }^{6}$, mas sim aquelas que são correntemente evocadas 'ao se falar da' leitura, ou de si e do outro 'como’ leitores.

Se o discurso fornece o que é dizível sobre uma prática e sobre os sujeitos que a exercem, ele também regula o tipo de emoção consensualmente adequada na enunciação dessa prática. São principalmente dois os modos de expressão das emoções ao se enunciar sobre a leitura: I) quando se faz referência explícita a ela; 2) quando o modo de enunciar permite depreender um ou outro estado afetivo relativo à leitura. Assim como ocorre com tudo que pode e deve ser dito sobre uma determinada prática e sobre os sujeitos que a exercem, não é qualquer emoção que se evoca ou que se expressa a seu respeito, cabendo-nos, portanto, depreender, delimitar e descrever o funcionamento discursivo peculiar dos afetos quando enunciamos.

Interessei-me por este aspecto quando realizava a pesquisa anterior ${ }^{7}$, dedicada à análise do que era enunciado sobre o perfil leitor dos presidentes brasileiros Fernando Henrique Cardoso (I995-2002), Luiz Inácio Lula da Silva (2003-2010) e Dilma Rousseff (2OII-2OI6), nas maiores revistas e jornais de circulação nacional. Constatei haver uma grande recorrência ao tema da leitura, na maioria das vezes em referências bastante passageiras, gratuitas e alusivas. Apesar da frequência, não varia consequentemente o que se diz sobre a leitura. Além disso, Ao se evocar esse tema, é comum que sua exploração simbólica, nesses textos da mídia, como oportunidade para atribuição de bônus ou de descrédito a autoridades políticas em questão. Fernando Henrique Cardoso, Luiz Inácio Lula da Silva e Dilma Rousseff são representados respectivamente nesses textos, de modo quase caricatural, como o "leitor ideal", o "não-leitor" e a "leitora, no feminino".

Esse protocolo de representação impunha, mesmo em textos críticos à gestão do presidente Fernando Henrique Cardoso (FHC), a sua representação como leitor 'ideal', o que era manifesto tanto por meio de fotografias suas com livros, quanto por meio de menções verbais a sua relaçao com os livros e a leitura. Em sua maioria, essas menções às práticas de leitura de FHC se caracterizaram por sua gratuidade absoluta.

A apresentação do presidente Luiz Inácio Lula da Silva (Lula), em relação à leitura, também responde a um protocolo, mas, no seu caso, comprometido com a demonstração de sua condição avessa à de seu antecessor, sendo apresentado como 'não-leitor'. Seja sob a forma do silêncio em relação ao que leria ou da negação sistemática e enfática de que leria, e no caso desta última, enunciada pelo recurso constante ao humor e à ironia, as representações de Lula em relação à leitura são ora invisibilizadas, ora negadas e, quando

\footnotetext{
${ }^{6}$ A esse respeito, há uma bibliografia importante, tanto no campo da História cultural, quanto da Nova retórica e de certas linhas da Análise do discurso, que se voltaram para a análise das emoçoes resultantes da leitura ou da escuta de certos textos, em especial dos textos literários e políticos. A título de exemplo, cf. Lyon-Caen (2OI6), que se dedica à análise das emoções expressas nos textos literários com vistas a suscitá-las no público leitor; e autores do campo de estudos da Retórica argumentativa, dedicados ao pathos, que se voltam especialmente à consideração dos efeitos da argumentação que anuncia a emoção que quer fomentar no público ou que apela à subjetividade emotiva do público.

7 "Divisões sociais da leitura no Brasil: uma análise discursiva das representacões da mídia sobre os políticos como leitores", pesquisa desenvolvida, no quadro de um pós-doutoramento, na Université de Versailles Saint-Quentin-enYvelines, sob a supervisão dos professores Jean-Claude Yon e Jean-Yves Mollier, com apoio FAPESP (20I6/o67249) de $20 \mathrm{OI}$ a $20 \mathrm{O} 8$.
} 
negadas isso é feito prioritariamente de forma a ridicularizá-lo, recorrendo em geral ao estereótipo do analfabeto (Cf. Curcino 20I8; 20I9).

Em relação à presidenta Dilma Rousseff (Dilma), além de menos frequente, se comparadas às reverências relativas aos seus dois antecessores, sua apresentação como leitora retoma os dois protocolos anteriores, mas ainda assim com diferenças não negligenciáveis: I) afirma-se sua condição leitora, seu gosto pela leitura e seu hábito, tal como em relação a FHC; 2) nega-se ou deprecia-se sua condição leitora, tal como em relação a Lula. No entanto, quando são feitas as referências a ela como leitora não lhe outorgam os mesmos benefícios simbólicos tal como a FHC: ora, elas são enunciadas como um mero álibi para, comparativamente, depreciar seu antecessor, Lula; ora elas são eivadas de um viés sexista, que a representa conforme representações 'feminilizantes' da leitura, em grande medida depreciativas e que remontam a estereótipos que foram produzidos e circularam sobre a mulher leitora especialmente no século XIX europeu. O modo como se faz referência a suas práticas de leitura durante o exercício de suas funções presidenciais é apresentado como inadequado, porque ela leria ‘demais', leria ‘tudo', leria 'linha-por-linha', leria em excesso, o que atravancaria suas decisões e as ações do governo. $\mathrm{O}$ modo como se faz referência a suas práticas de leitura privadas, para formação e entretenimento, também é apresentado como inadequado, seja porque ela é representada lendo autores subversivos, seja porque o faz para evadir da realidade. Segundo essas representações, ela leria de forma excessiva, compulsiva, subversiva e evasiva, conforme estereótipos duradouros acerca da mulher (Cf. Curcino, 2O2Oa).

As avaliações que sobre eles recaíram me interessaram não pelos pontos de vista da mídia a respeito do perfil leitor de políticos de relevo no país. Meu interesse pelo que foi dito acerca deles como leitores se justifica por sua condição metonímica do que em geral é dito sobre os brasileiros em sua relação com a leitura. Com a análise desses dados foi possível ouvir o eco de "lutas de representação", como as nomeou Roger Chartier (2OII), lutas difusas, cotidianas e de longa data, responsáveis pela reprodução de certos discursos, por sua aceitação como verdade, por seus usos como meio de julgamento e hierarquização dos sujeitos, enfim, pela incorporação dos modos de ser que eles nos fornecem.

Foi a partir das análises realizadas nessa pesquisa anterior que me deparei com a evocação relativamente recorrente de certas emoções em relação à leitura. Alguns dos enunciados que compunham o corpus coletado continham apreciações nostálgicas de um passado idealizado, no qual se leria mais e melhor, comparado a um presente de hábitos de leitura degradados ou inexistentes. Essas alusões nostálgicas por vezes vinham acompanhadas da expressão de orgulho ou de vergonha, próprios ou alheios, em relação ao que se enunciava sobre a leitura e sobre os leitores. Observei, assim, que uma forma recorrente de enunciar a leitura atualizava 'certas' emoções, a saber, a 'vergonha' e o 'orgulho’,

\footnotetext{
${ }^{8}$ Quanto às formas de expressão nostálgicas em relação à leitura, constatei haver tanto aquelas referentes à nostalgia do vivido num passado menos distante quanto a nostalgia do não-vivido, quando se faz referência a um passado que não se viveu, e por isso mais facilmente idealizável. Em função de sua estreita relação com as formas de evocação do orgulho ou da vergonha, optei metodologicamente por não tratar especificamente da nostalgia, embora possa a ela aludir nas análises desses dois outros afetos mais regularmente expressos.
} 
que eram geralmente manifestas de forma genérica, sugestiva ou aproximada. Foi assim possível observar que: I) estabelece-se, no horizonte discursivo do que enunciar sobre 'certas’ práticas como a leitura, a referência a 'certas' emoções, e não a qualquer uma, nem de qualquer modo; 2) as emoções evocadas engendram-se umas às outras, ou seja, as alusões à 'nostalgia' ensejam, por vezes, a manifestação de 'vergonha', e as alusões à 'vergonha' alheia indiciam a desidentificação do enunciador em relação àquele de cujas práticas ele tem ‘vergonha' e, por extensão, expressam seu 'orgulho' dessa sua diferença autoalegada ${ }^{9}$.

Apesar de "parecerem existir fora do tempo" e de "sugerirem experiências comuns" ao longo das épocas, as emoções variam.

O medo, a vergonha, a cólera, a alegria, atravessam sem dúvida o tempo, parecem ter sido vividas, "sentidas”, de modo comum de uma época a outra, mas elas variam com os indivíduos, com as culturas, e com as sensibilidades. Elas têm seus estados, suas modulações, elas se alteram, se singularizam, revelando uma dispersão de possíveis para além de sua ampla existência genérica. (Corbin, Courtine e Vigarello, 2OI6: $5^{-6)}$

Para esses historiadores, não se trata " $a$ priori de colocar em xeque a existência [das emoções tais] como a tristeza, a alegria, a cólera ou o medo", mas antes considerar que o seu sentido muda assim como "suas formas, suas nuances, sua intensidade", o que justifica "a legitimidade de uma história das emoções", segundo Corbin; Courtine e Vigarello (2оі6: 6).

Embora as emoções tenham sido consideradas como próprias da condição humana, logo, universais e naturai ${ }^{\mathrm{IO}}$, ou ainda como a expressão subjetiva ${ }^{\mathrm{II}}$ do que vivenciamos individualmente, não é segundo essas perspectivas que as levo em conta em minha análise. A abordagem histórico-discursiva dedicada às emoções, tal como expressa por esses historiadores, me interessa na medida em que ela se ocupa não da história de uma emoção ao longo do tempo. Diferentemente, eles dão relevo à análise de suas atualizações específicas, em contextos determinados e a suas evocações com papéis próprios e com efeitos de sentido variados. Segundo a perspectiva adotada por esses historiadores, não se visa a priori empreender uma história total, de longa duração e genérica de uma emoção específica. Antes, objetivam depreender e descrever um dado afeto em sua condição de 'acontecimento' discursivo e histórico.

\footnotetext{
9 Para a análise, recorro aos estudos dedicados às emoções, de viés histórico, cultural e discursivo que vêm sendo realizados por Courtine \& Haroche (1995); Courtine (2OI6); Courtine (2020); Haroche (20I7) entre outros.

Io No final do século XIX, Charles Darwin publica seu livro "Expressão das emoções no homem e nos animais", afirmando o seu caráter universal e as formas prototípicas de expressá-las corporalmente.

II Segundo diferentes vertentes, a Psicologia se encarregará de compreender a manifestação emocional no nível dos individuos, ainda que essa abordagem e suas constataçốes sejam passíveis de generalização e de caracterização de grupos.
} 
Na esteira dessa abordagem, considero que as emoções relacionadas à leitura são enunciadas, tais como o são, porque se subordinam às posições dos sujeitos que as enunciam $^{12} \mathrm{e}$ porque se inscrevem em discursos consensuais sobre essa prática.

\section{O presidente Lula e a leitura: a expressão midiática de vergonha alheia}

De modo a ilustrar a ocorrência desse tipo de enunciado que mobiliza emoções relativas à leitura, apresento uma breve análise de um texto da mídia brasileira no qual se faz, ainda que de maneira muito alusiva, referência ao presidente Lula e sua relação com a leitura. Não é segredo de estado, a origem popular deste presidente. Ele sempre foi um outsider cultural na política, particularmente entre os presidentes brasileiros até sua eleição. Tal como demonstrei em Curcino (20I8; 20I9), sua participação nas disputas eleitorais à presidência suscitou a exploração mais intensa e recorrente de sua relação com a cultura letrada.

No enunciado que analiso na sequência, a expressão da vergonha é mobilizada de forma relativamente direta e explícita. Mais especificamente, ela corresponde à expressão de "vergonha alheia", ou seja, da vergonha que se sente de um outro em função de seu comportamento que alguns consideram reprovável e que sabemos ser considerado reprovável por outros que compartilham dessa mesma opinião, avaliação e comportamento. Na expressão de vergonha alheia, o enunciador estabelece uma distância do outro a quem reprova seja o que ele disse, seja o que ele fez. Esse enunciado consta de um artigo publicado em $2004 \mathrm{em}$ um dos principais jornais de maior circulação no Brasil, a Folha de São Paulo, na ocasião em que Lula, já como presidente, participa da abertura da Bienal Internacional do Livro de São Paulo, maior evento do gênero na América Latina:

\section{Enunciado I:}

Lula causa constrangimento ao comparar livro a aparelho de ginástica

O presidente Luiz Inácio Lula da Silva causou constrangimento nesta quinta-feira, durante discurso na abertura da I8 ${ }^{\text {a }}$ Bienal do Livro, ao comparar um livro a uma esteira de ginástica. "Um livro para uma criança, é como uma esteira para alguém da nossa idade”, disse. “Dá preguiça começar, mas depois de uns vinte minutos a gente vê como é importante." ${ }^{\text {I3 }}$

Embora ele tenha sido o primeiro presidente da República a participar da abertura da Bienal Internacional do Livro de São Paulo e de em seu discurso ter assumido o

\footnotetext{
I2 Ao se enunciar sobre a leitura, a 'vergonha' e o ‘orgulho' são as emoções protocolares que emergem. Essa emergência conta com uma relativa previsibilidade quando se considera a origem de classe daqueles que enunciam(se) em relação à leitura ou daqueles que são referidos na enunciação quando se fala dessa prática cultural. Elas fazem parte do repertório das formas de "injúrias ocultas de classe", para empregarmos o termo de Richard Sennet \& Jonathan Cobb (i972).

${ }^{13}$ In: Folha Online - Folha de São Paulo, seção Poder, I5 de abril de 2004.
} 
compromisso de criação de bibliotecas públicas nos I.ooo municípios brasileiros que, em pleno século XXI, ainda não contavam com essa estrutura pública de acesso aos livros, ainda assim o foco do texto é a dita "gafe" cometida por Lula da Silva ao falar da leitura. Essa gafe vai ocupar as linhas da maior parte deste texto, vai figurar no seu título e vai ser repercutida em diversos outros textos à época, sendo reproduzida, parafraseada, citada por diversos jornalistas e comentada por diferentes leitores. Tornou-se uma frase recitável e autônoma, e para cuja interpretação não carece de contextualização. Sua mera citação pressupõe que ‘todos sabem’ que ela 'é’ uma declaração a se condenar. Ela foi e é reiterada de diferentes maneiras por diferentes enunciadores. Ela é relembrada sempre que Lula faz novas declarações relativas à leitura. Um exemplo disso se encontra no enunciado 2, que se trata de um fragmento de um texto de Augusto Nunes, jornalista que publica na coluna 'Radar' da Revista Veja, revista do segmento de informações semanais com a maior circulação no país. De início, o jornalista traz a citação de parte da carta escrita por Lula e lida na abertura do "V Salão do Livro Político", realizado de 27 a 3 o de maio de 20ı9, na qual ele afirma a importância política da leitura. Após a citação, o jornalista inclui, entre parênteses, um comentário bastante derrisório, revisitando a comparação feita por Lula, I5 anos antes, na abertura da Bienal Internacional do Livro de São Paulo, como um recurso para a deslegitimação do que enuncia Lula nesta carta.

\section{Enunciado 2:}

“Ler é um ato político. Não é por acaso que nossos adversários, ao mesmo tempo que tentam criminalizar a política e impedir toda e qualquer forma de ativismo, atacam com tanto ódio o saber, o conhecimento. Querem mais armas e menos livros. Mais jovens presos e abatidos por disparos de helicópteros do que com acesso ao ensino público de qualidade". (Lula, numa carta lida na $5^{\text {a }}$ edição do Salão do Livro Político, treinando para virar humorista ao fingir que nunca disse que "leitura é pior que exercício em esteira", nem que "não estudei porque sempre fui preguiçoso"). ${ }^{\mathrm{I}}$

Essa mesma referência é citada ainda, e também com valor disfórico, mesmo em textos cujo posicionamento do enunciador adota uma orientação argumentativa mais descritiva, e até positiva em relação ao presidente Lula da Silva:

Enunciado 3:

Dilma Rousseff e Michel Temer são leitores ávidos e frequentes. Sarney convenceu Temer a recriar o Ministério da Cultura e foi autor da Lei do Livro, sancionada pelo então presidente Luiz Inácio Lula da Silva, que regulamentou o setor literário e instituiu programas de fomento à

\footnotetext{
${ }^{14}$ Nunes, Augusto. Lula lê. O ex-presidente presidiário finge que nunca disse que "leitura é pior que exercício em esteira”. In: Revista Veja. Política, Seção Radar, Coluna do Augusto Nunes, de 29 de maio de 20I9. Disponível em: https://veja.abril.com.br/blog/augusto-nunes/sanatoriogeral-lula-le/ . Consulta em: 28/o9/2020.
} 
leitura. Na abertura da Bienal Internacional do Livro de São Paulo, em 2004, Lula fez a infeliz comparação de um livro a uma esteira de ginástica: "Dá preguiça começar, mas depois de vinte minutos a gente vê como é importante." Com o tempo, Lula se converteria à leitura. Divulga-se hoje, equivocadamente, que ele começou a ler na prisão em Curitiba. Na verdade, ele se tornou um leitor frequente em 2OII, quando se submeteu ao tratamento do câncer na laringe. Na ocasião, leu as biografias de Getúlio, João Goulart, Franklin Roosevelt, Nelson Mandela. ${ }^{5}$

Em unívoco, textos diversos e as centenas de seus comentários condenam a metáfora empregada pelo presidente, condenam o que consideram ser uma inadequação de sua declaração e um erro típico de quem não é leitor. O autor do texto de que faz parte o primeiro enunciado afirma que "Lula causou constrangimento". Essa afirmação foi feita sem se especificar a quem se constrangeu, tal como a morfossintaxe dessa construção linguística exigiria. O pressuposto é o de que nesse universo dos que leem, dos que organizam, participam e visitam uma bienal do livro seria natural que "todos" se sentissem constrangidos diante de tal comparação, tida por inapropriada e maculadora da imagem do livro e da leitura. A citação em discurso direto do que enunciou o presidente vai ao encontro desse pressuposto, uma vez que é usada como um argumento que prova, que demonstra a razão da tese afirmada pelo enunciador segundo a qual o que Lula disse em relação à leitura foi algo constrangedor, em si mesmo, assim como em função do público e da ocasião de sua declaração.

Conforme discurso consensual e de longa data, a leitura é prática em geral comparada a atividades intelectuais e de prestígio cultural. Para os que aderem a esse discurso, compará-la a um exercício físico em uma esteira seria, em alguma medida, um modo de banalizá-la, de igualá-la a outras atividades menos nobres, de diminuir sua aura distintiva. De acordo com esse mesmo discurso, ela é uma prática prazerosa e edificante, por isso afirmar que se pode ter "preguiça para começar” é também um dizer sacrílego, não condizente com aquilo que se deve e se pode enunciar sobre essa prática, e particularmente não condizente com o enunciável na ocasião em questão.

Dirigir-se a frequentadores de bienais do livro, em uma seção de abertura de uma bienal dessa envergadura parece ter acrescentado ao que o presidente enunciou uma maior gravidade. Talvez por essa razão, o enunciador do texto do qual provém o enunciado I tenha escolhido reproduzir as palavras do presidente, em discurso direto. Essa escolha desempenhou duas funções: a de estabelecer uma distância do autor do texto com aquilo que foi enunciado pelo citado; a de ostentar o que o outro disse como a prova de um 'absurdo', opinião que o autor sabe que seu leitor também compartilha acerca do tema, desse leitor que lê jornal e que lê este jornal em que ele escreve. Trata-se de um exemplo claro do funcionamento descrito por Michel Foucault (I999) do princípio da

\footnotetext{
I5 Jubé, Andrea. Bolsonaro e os presidentes que liam. In: Jornal Valor Econômico. Seção Política, de i8 de fevereiro de 202O. Disponível em: https://valor.globo.com/politica/coluna/bolsonaro-e-os-presidentes-que-liam.ghtml Consulta em: 29/o9/202O.
} 
rarefação no controle dos discursos: não é qualquer um que pode dizer qualquer coisa, muito menos de qualquer modo, sobre certos temas, nem em qualquer ocasião. Lula é desautorizado quanto ao que disse, não apenas em função do que disse, mas também e talvez principalmente por não ser reconhecido como leitor e por isso não ser reconhecido como alguém que teria o que dizer sobre a leitura e gozaria de legitimidade para fazê-lo.

Esse pressuposto de que o que disse o presidente "causou constrangimento" se baseia em uma essencialização da leitura, própria dos discursos hegemônicos sobre essa prática, a ponto de se interditar qualquer metáfora que a assemelhe a práticas tidas como menos nobres, não intelectuais, que a alinhem a atividades físicas, que a destituam de sua nobreza alegada e de seu caráter sublime. Embora tecnicamente ela possa ser exercida por muitos de nós, nem todos se reconhecem ou são reconhecidos como leitores, frente à imagem idealizada dessa prática cultural, caracterizada pela precocidade, gosto, constância, espontaneidade e prazer na leitura de certos livros, cujos títulos e autores componham algum cânone. Esse reconhecimento advém ainda de certas formas consideradas 'adequadas' de se manifestar a respeito da leitura, em consonância com essas características do leitor 'ideal' e segundo um repertório relativamente restrito do que dizer sobre essa prática, logo, do que não dizer a seu respeito, sob o risco de ser desqualificado.

A reprodução do que disse o presidente, sob a forma de discurso direto, visa ao efeito de veridicção, mas ao mesmo tempo indicia a finalidade irônica e condenatória do enunciador, se considerarmos a posição de reprovação expressa pelo mesmo desde o título e reafirmada no corpo do texto como algo que "causa/causou constrangimento". As escolhas verbais não dão margem à dúvida: o presente e o pretérito perfeito são tempos assertivos.

A desqualificação derrisória do que afirmou o ex-presidente Lula sobre a leitura tem origem, portanto, em uma desautorização prévia daquele que enuncia, que não sendo reconhecido como leitor, como um "verdadeiro leitor", não saberia falar da leitura, e por isso não deveria falar dela, porque não sendo leitor e ainda assim se atrevendo a falar do tema só poderia fazê-lo de forma equivocada, cometendo gafe, produzindo constrangimento, gerando vergonha alheia nos “verdadeiros" leitores.

Esse modo derrisório de enunciar tem como função, segundo Arnauld Mercier (2OOI), a de ridicularizar aquele ou aquilo de que se fala, tornar desimportante algo ou alguém, rebaixá-lo, e isso por meio, muitas vezes, da ironia ou do humor, cujo recurso visa ao efeito de menosprezo ou desdém, visa estabelecer uma distância entre quem enuncia e aquele de quem se fala derrisoriamente. Ao se ironizar a afirmação de Lula, se constrói, pelo mesmo gesto, uma autoafirmação positiva, orgulhosa de si, em relação a uma prática e ao status vinculado culturalmente a essa prática. A derrisão

está fundamentalmente ligada à afirmação de si. Valer-se da derrisão é um ato que visa reafirmar sua própria existência, reafirmação associada à vontade de demarcar sua superioridade em relação àquele a quem se dirige uma derrisão. [...] A derrisão, ao eleger uma vítima, ao escolher um 
bode expiatório ao qual destina atributos depreciativos, conforta o ego daquele que é responsável pela derrisão em sua identidade e em seu sentimento de superioridade. [...] O mesmo mecanismo funciona ao se passar para a escala coletiva de afirmação do grupo. (Mercier, 200I: I2) ${ }^{16}$

A análise desse tipo de representação de Lula como não-leitor é importante porque não se restringe a ele. É antes uma metonímia da representação consensual que se faz de grande parte dos brasileiros, tal como afirmei antes, e em Curcino (2018, 20I9, $2 \mathrm{O} 2 \mathrm{Ob})$. Estamos diante de um exemplo de vergonha social que se declara sobre um sujeito, que se lhe impõe não como sujeito apenas, mas como representante de um contingente de mesma origem, de mesma formação, de mesmas carências, submetidos aos mesmos estigmas e cujas identidades se formam nesse espelho deformado pela vergonha alheia que o outro the coloca em face, esse outro que lhe lembra de uma falta da qual se envergonhar, sempre, vergonha que deve ser herdada pelos seus, lembrada aos seus. $\mathrm{O}$ estigma dessa falta impõe um silêncio sobre as razões dessa falta. Os indivíduos preferem não dar mostras de sua condição de falta, e por isso silenciam sua condição, querem passar despercebidos, para o que é preciso por vezes reproduzir os mesmos discursos que os oprimem, ofendem e envergonham.

Aliás, são vários os textos na mídia brasileira que qualificam o presidente Lula como não-leitor, que desqualificam o que ele eventualmente disse sobre livros, autores ou leitura em diferentes ocasiões. No começo de sua carreira política, nos anos 8o, ele foi várias vezes, em diversas entrevistas, questionado se lia ou não, se era leitor ou não. E as declarações que ele deu nessas ocasiões foram sucessivas vezes retomadas em outros textos como forma de desqualificá-lo. Isso porque ele, nessas circunstâncias, admite não ler, se justifica como não tendo tempo para ler, assim como declara que não consegue se concentrar ao ler. Outras vezes, ele afirma ter preguiça de ler, assumindo, portanto, a "culpa" por esse comportamento não-leitor. Assumir a culpa, tal como observou Bourdieu \& Passeron (20I4), é uma das formas de lidar com a "vergonha" de não corresponder àquilo que se sabe que os outros esperam.

A vergonha é um afeto moral. Algo que se sente em função de uma reprovação coletiva de viés moral: “Todos deveriam ser leitores, porque ser leitor é essencialmente bom!", nos diz o discurso consensual. O que este discurso dominante não reitera da mesma forma, silencia ou ignora é que nem todos podem ser leitores.

Esse sentimento de vergonha e culpa espreita muitos brasileiros e se manifesta como uma experiência terrível de indigência cultural. A vergonha resulta de um tipo de sanção social. Esse sentimento tem o peso de uma carência humilhante e castradora, em diferentes graus, e que se traduz em declarações que conhecemos bem: 'Eu não tive leitura'; 'Eu não tenho muita paciência pra ler’; 'Eu nunca gostei muito de ler'; 'Eu tenho

\footnotetext{
I6 « [...] est fondamentalement liée à l'affirmation du moi. Tourner en dérision est un acte et donc une preuve de son existence, souvent associé à la volonté de marquer sa supériorité. [...] La dérision, par la désignation d’une victime expiatoire, investie de qualités dévalorisantes, conforte l'ego de chacun dans son identité et son sentiment de supériorité. [...] Le même mécanisme est à l'œuvre en passant à une logique collective d’affirmation du groupe »
} 
uma preguiça de ler’; ‘Eu não tenho tempo pra ler’; 'Eu não consigo me concentrar’, 'Eu nunca fui muito desse negócio de leitura'.

Somos levados a ouvir e interpretar essas declarações frequentes como a expressão de uma realidade: "há quem goste e há quem não goste de leitura"; "há quem leia frequentemente e há quem prefira fazer outras coisas"; "há quem tenha preguiça de ler e quem não", e assim por diante. Em geral ignoramos as condições materiais, as violências simbólicas e as carências intelectuais que são impostas a estes que não têm outra alternativa a não ser se apresentarem como não-leitores. Tão convincente e potente é esse tipo de violência simbólica a ponto daqueles que foram privados da leitura serem convencidos de que não são leitores e serem convencidos a assumir a responsabilidade por não serem leitores. Diante do embaraço de ter de falar de si como alguém que não é leitor, como alguém que não lê, a forma mais nobre parece ser a de admitir isso como se se assumisse uma culpa, uma falha, um erro individual, adotando uma estrutura muito prototípica, com o uso da primeira pessoa verbal "eu" e da negativa que precede o verbo: 'não tive', 'não entendo', ‘não tenho paciência', ‘nunca gostei', ‘não sou’, 'não consigo'. Essa enunciação em primeira pessoa, e plena de negativas, indicia claramente o gesto de admissão e de antecipação de uma culpa individual, em um autojulgamento muitas vezes severo e resignado. Tal como afirmam Bourdieu \& Passeron (2OI4), além desse autojulgamento severo e resignado (eu sou assim), é comum se reivindicar o que se é e se faz (eu quis ser assim, eu escolhi ser assim), assumindo como escolha individual aquilo que a sociedade lhe impôs. Por isso é tão comum a 'reivindicação', da condição de não-leitor nas declarações de Lula e de muitos que, como ele, tiveram a mesma origem social e viveram o mesmo alijamento das práticas culturais de prestígio. Assumir como culpa ou como escolha é a forma aparentemente mais digna de lidar com algo a que se foi condenado a ser, sem que se tenha consciência dessa condenação, nem de que se faz coro àquilo e àqueles que o condenaram a não ter escolha.

\section{Algumas Considerações}

Não sendo possível ‘ser' nem 'corresponder' às expectativas do grupo a que se pertence, são reações emocionais possíveis para se lidar com o sofrimento da 'vergonha': i) a de se resignar com a inevitabilidade de sua condição de não-leitor; ii) a de se tornar indiferente com isso que não se pode ser, relativizando a importância da leitura; iii) a de reagir de forma sarcástica para mascarar sua vergonha e manifestar sua indignação diante do que lhe foi negado; iv) a de desenvolver seu ressentimento, que tem por consequência questionar o próprio valor da prática e não das estruturas que impedem a maioria de exercê-la. Outra reação possível, mas mais incomum, é a da apropriação de uma "metalinguagem da emancipação”, conforme descrita por Piovezani (2O2O). Trata-se da posição assumida pelo sujeito que, reconhecendo essas injunções dominantes, em seu funcionamento perverso, subverte o que se espera que ele diga ou faça, e empreende a denúncia 
sistemática dessa lógica da reprodução e da distinção que organizam a vida em sociedade, tal como a conhecemos.

A enunciação das emoções da 'vergonha' e do 'orgulho’ relativas à condição leitora, ou seja, à condição de ser ou de não ser leitor, em uma sociedade letrada como a nossa, resulta desse processo discursivo e ao mesmo tempo o constitui, fornecendo aos sujeitos maneiras de se identificar com essa condição leitora. A enunciação nostálgica de um passado no qual se cria ler mais e melhor, a expressão de orgulho ou de vergonha derivados da identificação com a representação idealizada do que é ser leitor, ou da consciência da distância entre as práticas que se exerce e aquelas consideradas ideais, fornecem e ampliam o rol de enunciados constituintes dos discursos consensuais sobre a leitura.

Os discursos, como matrizes do enunciável e do significável, como determinantes do dizível e de suas formas específicas, assim como do interpretável dessas formas, apenas podem ser depreendidos a partir da análise do que foi efetivamente enunciado, em textos efetivamente produzidos, e tal como o que se enunciou foi formulado e encontrou com isso condições favoráveis de circulação e de inscrição no já sabido, no já concebido como verdade por sujeitos, num dado tempo e espaço.

As emoções que enunciamos, seja nominalizando-as, seja apenas aludindo a seus traços característicos, expressam um modo de avaliar em conformidade com valores coletivamente validados. Evocar a 'vergonha' em relação a uma dada prática de leitura do outro, tal como no enunciado analisado, pressupõe inscrever-se em convenções socialmente compartilhadas e relativamente estabilizadas quanto ao que se pode e se deve dizer a esse respeito. Essa evocação, por sua vez, apenas produz os efeitos de sentido que produz, visados por aquele que enuncia, em função do funcionamento discursivo de uma memória ${ }^{17}$, reguladora e responsável pelas concepções e avaliações prévias que categorizam o que é digno de rememoração nostálgica, o que é vergonhoso ou fonte de orgulho em uma sociedade, para um certo grupo e sempre em contraste com outros sujeitos, de outros grupos.

Considero fundamental para a reflexão sobre a leitura e para a adoção de práticas de ensino e de incentivo a essa prática compreender o funcionamento dos discursos que a qualificam e, por extensão, aos sujeitos que a empreendem. Essas formas de qualificação são responsáveis pela proximidade ou distância que os sujeitos reconhecerão quanto ao que fazem e ao modo como vivenciam a prática de leitura. A reflexão sobre os discursos sobre a leitura, e entre eles aqueles que exploram a alusão a certas emoções, tem assim um papel importante na descrição dessa economia valorativa da leitura e com ela na desmistificação das distâncias imputadas àqueles que sem condições de experenciar as emoções idealizadas, ainda assim as adotam como parâmetro para se autojulgarem ou para validarem os julgamentos dos outros que lhes são dirigidos, e que como os primeiros não dispõem das mesmas condições sociais, materiais, concretas e ideais para ser leitor.

\footnotetext{
${ }^{17}$ Segundo Courtine (2009, p.IO5) "a nocão de memória discursiva diz respeito à existência histórica do enunciado no interior de práticas discursivas regradas por aparelhos ideológicos; ela visa o que Foucault (I97I, p. 24) levanta a propósito dos textos religiosos, jurídicos, literários, científicos, discursos que originam um certo numero de novos atos, de palavras que os retomam, os transformam ou falam deles, enfim, os discursos que indefinidamente, para além de sua formulação, são ditos, permanecem ditos e estão ainda a dizer"”.
} 


\section{Referèncias Bibliográficas}

- Bourdieu, P.; Passeron, J-C. (2OI4). Os Herdeiros - os estudantes e a cultura. Florianópolis: EdUFSC.

- Chartier, R. (2OII). Uma trajetória intelectual: livros, leituras, literaturas. In Rocha, J. C. de C. (org.). Roger Chartier - A força das representações: história e ficção. Chapecó: Argos.

- Chartier, R. (2017). Leer sin libros. Revista Álabe. I5 (pp. I-3). DOI: http://dx.doi. org/Io.I5645/Alabe2OI7.I5.Io. Disponível em: http://revistaalabe.com/index/alabe/article/view/398/264.

- Courtine, J-J. (2009). Orientações Teóricas da Pesquisa. In Análise do discurso político: o discurso comunista endereçado aos cristãos. São Carlos: EdUFSCar.

- Courtine, J-J. e Haroche, C. (I995). História do rosto: exprimir e calar as suas emoções (do século XVI ao início do século XIX). Lisboa: Teorema.

- Courtine, J-J. (20I6). A era da ansiedade: discurso, história e emoções. In Curcino, L.; Sargentini, V.; Piovezani, C. (orgs.). (In)Subordinações contemporâneas: consensos e resistências nos discursos. (pp. I5-29). São Carlos: EdUFSCar.

- Courtine, J-J. (202O). O medo na era da ansiedade. In Corbin, A., Courtine, J-J. e Vigarello, G. (orgs.). História das emoções: Do final do século XIX até hoje. Rio de Janeiro: Vozes.

- Curcino, L. (20I8). Imprensa e discursos sobre a leitura: representações dos presidentes FHC, Lula e Dilma como leitores. In EID\&A - Revista Eletrônica de Estudos Integrados em Discurso e Argumentação, Ilhéus, n. I6, Edição Especial "Discurso e argumentação na política latino-americana", set. (pp. 223-243). Disponível em: http://periodicos.uesc.br/index. php/eidea/article/view/2223.

- Curcino, L. (2019). Discursos sobre a leitura: do elogio ao insulto na construção do perfil leitor de políticos. In Hossne, A. S.; Nakagome, P. T. (orgs.). Leitores e leituras na contemporaneidade. (pp. II2-I28). Araraquara: Letraria. Disponível em: https://www.letraria.net/ leitores-leituras/.

- Curcino, L. (2O2Oa). La femme qui lit: stéréotypes sexistes dans les représentations de Dilma Rousseff en tant que lectrice dans les médias au Brésil. In Texte \& Contexte. [Online]. Número Temático: Les femmes américaines entre féminisation du politique et politisation de l’intime. n. I5, vol. 2, dez 202O. (pp. I-9). Universidade de Bourgogne - França. Disponível em: http://preo.u-bourgogne.fr/textesetcontextes/index.php?id=2935. 
- Curcino, L. (2O2Ob). Infames e penetras no universo da leitura: princípios da arqueologia foucaultiana em uma análise de discursos sobre essa prática. In Moara. Número temático: 50 anos de "A Arqueologia do Saber": as contribuições aos estudos da linguagem no Brasil. Vol. I, n. 57, ago/dez de 202O. (pp. 74-9I). Disponível em: https://periodicos.ufpa.br/index. $\mathrm{php} / \mathrm{moara} /$ article/view/8874.

- Foucault, M. (I999). A ordem do discurso. São Paulo: Edições Loyola.

- Foucault, M. (2000). Arqueologia do Saber. Rio de Janeiro: Forense Universitária.

- Haroche, C. (20I7). Le sentiment d'humiliation: dégrader, rabaisser, détruire. In Corbin, A. Courtine, J-J. e Vigarello, G. (orgs.). Histoire des Émotions: de la fin du XIXe siècle à nous jours. Paris: Seuil.

- Lyon-Caen, J. (20I6). Le “je” et le baromètre de l'âme. In Corbin, A. Courtine, J-J. e Vigarello, G. (orgs.). Histoire des Émotions: des Lumières à la fin du XIX ${ }^{e}$ siècle. Paris: Seuil.

- Mercier, A. (200I). Pouvoirs de la dérision, dérision des pouvoirs. Hermés - Dérision Contestation' (pp. 9-I9), n. 29. Paris/Université de Nice: CNRS Éditions. Disponível em: http://documents.irevues.inist.fr/handle/2042/I4482.

- Piovezani, C. (2020). A voz do povo: uma longa história de discriminações. Petrópolis: Vozes.

- Sennett, R.; Cobb, J. (1972). The hidden injuries of class. New York: W.W. Norton. 